九州大学学術情報リポジトリ

Kyushu University Institutional Repository

\title{
Environmental Efficiency and Economic Losses of Vietnamese Tea Production: Implications for Cost Savings and Environmental Protection
}

Nguyen, Bich Hong

Laboratory of Environmental Economics, Department of Agriculture and Resource Economics, Graduate School of Bioresource and Bioenvironmental Sciences, Faculty of Agriculture, Kyushu University / Thai Nguyen University of Economics \& Business andAdministration

Takahashi, Yoshifumi

Laboratory of Environmental Economics, Division of Agricultural and Resource Economics, Department of Agricultural and Resource Economics, Faculty of Agriculture, Kyushu University

Yabe, Mitsuyasu

Laboratory of Environmental Economics, Division of Agricultural and Resource Economics,

Department of Agricultural and Resource Economics, Faculty of Agriculture, Kyushu University

https://doi.org/10.5109/1686503

出版情報：九州大学大学院農学研究院紀要. 61 (2)，pp.383-390，2016-09-01. Faculty of Agriculture, Kyushu University

バージョン：

権利関係 : 


\title{
Environmental Efficiency and Economic Losses of Vietnamese Tea Production: Implications for Cost Savings and Environmental Protection
}

\author{
Nguyen Bich HONG ${ }^{1,2}$, Yoshifumi TAKAHASHI and Mitsuyasu YABE* \\ Laboratory of Environmental Economics, Division of Agricultural and Resource Economics, \\ Department of Agricultural and Resource Economics, Faculty of Agriculture, \\ Kyushu University, Fukuoka 812-8581, Japan \\ (Received April 28, 2016 and accepted May 10, 2016)
}

\begin{abstract}
Chemical fertilizer and pesticide are widely used by tea farmers in Vietnam to increase yield and combat risk associated with pests and diseases. However, their indiscriminate use can lead to various environmental problems. This study utilizes stochastic frontier analysis to measure the environmental efficiency of Vietnamese tea farms, taking explicitly into account the economic effects of chemical fertilizer and pesticide on tea production. We find that these environmentally detrimental inputs are overused in the farms, and there is considerable scope for decreasing their application with the current technology. Agricultural policies considering both the production and the environmental efficiency of chemical fertilizer and pesticide may assist tea farmers to save production costs and conserve the environment.
\end{abstract}

Key words: Tea farming, environmental efficiency, stochastic frontier analysis, Vietnam

\section{INTRODUCTION}

Tea is the second most popular beverage next to water and is an important commodity in terms of jobs and export earnings for a number of tropical developing countries. Millions of livelihoods around the world depend on tea picking and processing. In Vietnam, tea has been cultivated and drunk for thousands of years. Today, Vietnam is one of ten largest tea producers in the world. Tea production is an important source of national income (exported 146,700 tons and grossed 224.6 million dollars in 2012) (VietnameseTeaAssociation 2012). As a labor intensive industry, the tea sector offers employment year-round to about 400,000 small households in rural areas, in addition to creating over 1.5 million jobs in other parts of the tea value chain (GSO 2011). Despite its importance to developing countries' economic development, like any intensive monocropping, tea production's environmental impact is considerable. In a review of six major tea producing countries (India, Indonesia, Sri Lanka, Kenya, Vietnam and Malawi), Van Der Wal (2008) reports that abundant application of chemical inputs is negatively affecting the local and wider environment in some countries such as India, Sri Lanka and Vietnam. Pesticides and chemical fertilizers are often used in tea farming to restore nutrients used by tea bush and to fend off parasites. The resulting soil degradation is a major issue that farmers usually address by using even more fertilizers and chemicals, which further compounds the soil degradation problem. Chemical runoff into

Laboratory of Environmental Economics, Department of Agriculture and Resource Economics, Graduate School of Bioresource and Bioenvironmental Sciences, Faculty of Agriculture, Kyushu University, 6-10-1, Hakozaki, Higashi-ku, Fukuoka City, Japan

Thai Nguyen University of Economics \& Business and Administration, Thai Nguyen province, Vietnam

* Corresponding author (E-mail: yabe@agr.kyushu-u.ac.jp) waterways can also be a problem. The negative impact of excessive pesticide and agrochemical use in tea production on productivity, environment and human health (indirectly by retaining residues in tea products, water and soils) poses a grave threat to the sustainability of the tea farming system. Addressing the emerging issues requires the adoption of technologies and practices that do not have adverse effects on the environment and are easily accessible and effective for tea farmers. This raises the challenge to reduce environmental pollution while sustaining tea productivity levels with the given sets of technology. Thus, the integration of environmental performance into technical and economic efficiency measures of tea production is essential.

The literature on technical efficiency estimation in tea production can be found in Basnayake and Gunaratne (2000), Saigenji and Zeller (2009), Baten et al. (2010), Haridas et al. (2012), and Hong and Yabe (2015). Research integrating technical, economic, and environmental performance measures in tea production is, however, relatively scarce. Nghia (2008) evaluates economic and environmental impacts of transition from conventional to organic tea production in Thai Nguyen province of Vietnam. The study clearly shows that switching to organic tea production could bring economic benefits for the country's farmers and reduce the amount of agrochemical residue. The environmental impact of organic tea production was assessed through laboratory analysis of soil, water and tea samples collected monthly. To our knowledge, there has been no study conducted to estimate the environmental efficiency of tea production that examines the producers' ability to reduce the environmentally detrimental inputs applied. The present study fills this gap. The objective of the present study is to analyze farm-level data and provide empirical evidence about the environmental efficiency in Vietnamese tea farming using a stochastic frontier approach. The findings provide insights into possible tea production improvements 
toward environment-friendly and sustainable development.

The paper unfolds as follows. The next section presents methodology and the data collection procedure, beginning with a brief review of environmental efficiency measurements before introducing the empirical model and data issues. Results are reported in Section 3. Discussion and policy implications are formulated in Section 4.

\section{METHODOLOGY AND DATA COLLECTION}

\section{Analytical Framework}

Diverse environmental performance indexes have been proposed in the past based on the adjustment of conventional productivity measures. They can be classified on the basis of whether they treat environmental impacts as inputs or outputs. The indexes are also categorized into those estimated using deterministic techniques, which can be either parametric or nonparametric, and those measured using stochastic techniques, which are only parametric.

Pittman (1983) was the first to develop an index of productivity change considering environmental effects as additional undesirable outputs. The author derives a translog multilateral productivity index that includes undesirable outputs (water and air pollution) as well as desirable outputs when assessing pulp and paper mills' productivity. Pittman's study not only made significant progress in multilateral productivity comparisons across firms, industries and countries but also suggested a valuable methodology for pollution control. However, the study ignores the bad inputs that are also pollutants. In addition, Pittman's productivity index calculation requires shadow prices because well-defined market prices do not exist for undesirable outputs.

Fare et al. (1989) also consider environmental effects as undesirable outputs. Utilizing the Pittman data, they include pollution measures in the production model and propose an "enhanced hyperbolic production efficiency measure" that examines the producers' ability to maximize desirable outputs and minimize either undesirable outputs and inputs or just inputs. They use nonparametric techniques known as Data envelopment analysis (DEA) to estimate their hyperbolic production efficiency. Different from a multilateral productivity index, the hyperbolic efficiency estimation uses output quantities and undesirable output emissions instead of shadow prices and considers the reduction of not only undesirable outputs but also bad inputs.

Pittman (1981) develops an environmental performance index in which pollution is modeled as an input in the production function. The author suggests that the relation between environmentally detrimental inputs and outputs is similar to the relation between conventional inputs and outputs. Following this approach, Reinhard et al. (1999) study the effects of nitrogen pollution on intensive dairy farms in the Netherlands. They utilize a stochastic translog production frontier model in which nitrogen surplus (pollution variable) is treated as an additional input variable. They estimate technical efficiency (TE) and environmental efficiency (EE). Technical efficiency is calculated in conventional output orientation as the ratio of observed to maximum feasible output. The measurement of environmental efficiency is the input-oriented technical efficiency of a single input, as the ratio of minimum feasible to observed use of nitrogen surplus, conditional on observed levels of the desirable output and conventional inputs. Reinhard et al. (2000) repeat this analysis with an extension to multiple environmentally detrimental inputs such as nitrogen surplus, phosphate surplus and energy using both stochastic frontier analysis (SFA) and data envelopment analysis (DEA). Similarly, this paper estimates the environmental efficiency of tea production with multiple environmentally detrimental inputs using stochastic production frontier model.

The first step of environmental efficiency estimation is to calculate technical inefficiency, which measures the failure of a firm/producer to achieve the maximum output with given and obtainable technology (Farrell, 1957; Coelli et al., 1957). We assume that a tea farm produces a vector of single output denoted as $Y$, with $Y \in R_{+}^{M}$ using two types of inputs: conventional inputs (also known as normal inputs) $X\left(X \in R_{+}^{N}\right)$, and environmentally detrimental inputs (also known as bad inputs) $Z\left(Z \in R_{+}^{L}\right)$. The stochastic production frontier function of the $i$-th tea farm is defined as the following:

$$
Y_{i}=f\left(X_{i}, Z_{i}, \alpha, \beta, \delta\right) \exp \left(\varepsilon_{i}\right)
$$

Where: All farms are indexed with a subscript $i ; Y_{i}$ denotes the fresh tea yield level; $X_{i}$ is a vector of conventional inputs (with $X_{i 1}$ is the labour, $X_{i 2}$ is the water, $X_{i 3}$ is the capital, $X_{i 4}$ is the other cost); $Z_{i}$ is a vector of environmentally detrimental inputs (with $Z_{i 1}$ is the chemical fertilizer, $Z_{i 2}$ is the pesticide); $\alpha, \beta, \delta$ are parameters to be estimated; and $\varepsilon_{i}$ is the composed error term, which is equal to $v_{i}-u_{i}$. The term $v_{i}$ is a two-sided $\left(-\infty<v_{i}\right.$ $<\infty)$ normally distributed random error $\left(v \sim N\left[0, \sigma_{v}^{2}\right]\right)$ that represents the stochastic effects outside the farmer's control (e.g. weather, natural disasters and luck), measurement errors, and other statistical noise. The term $u_{i}$ is a nonnegative random error term, independently and identically distributed as $\mathrm{N}^{+}\left(0, \sigma_{u}^{2}\right)$, that represents the farm's technical inefficiency (Coelli et al. 2005).

Equation (1) is calculated by the maximum likelihood estimation (MLE) in order to create consistent estimators for $\alpha, \beta, \delta, \lambda$, and $\sigma$, where $\lambda=\sigma_{u} / \sigma_{v}, \sigma^{2}=\sigma_{u}^{2}+$ $\sigma_{v}^{2}$.

According to Battese and Corra (1977), the ratio variance parameter $\gamma$ that relates the variation of $u_{i}$ to total variation $\sigma^{2}$ can be calculated in the following manner:

$$
\gamma=\sigma_{u}^{2} / \sigma^{2}
$$

Such that $0 \leq \gamma \leq 1$

If the value of $\gamma$ is equal to zero, the difference between actual farmer yield and the efficient yield is entirely due to statistical noise. Conversely, a value of 1 
would indicate the difference attributed to the farmers' less-than-efficient use of technology, i.e. technical inefficiency (Coelli et al. 2005).

The technical inefficiency of an individual farm can be estimated using conditional distribution of $u_{i}$ given the fitted values of $\varepsilon_{i}$ and respective parameters (Jondrow et al. 1982 ). If we assume that $v_{i}$ and $u_{i}$ are independent each other, the conditional mean of $u_{i}$ given $\varepsilon_{i}$ is identified by:

$$
E\left(u_{i} \mid \varepsilon_{i}\right)=\sigma^{*}\left[\frac{f^{*}\left(\varepsilon_{i} \lambda / \sigma\right)}{1-F^{*}\left(\varepsilon_{i} \lambda / \sigma\right)}-\frac{\varepsilon_{i} \lambda}{\sigma}\right]
$$

Where: $\sigma^{* 2}=\sigma_{u}^{2} \sigma_{v}^{2} / \sigma^{2}, f^{*}$ is the standard normal density function, and $F^{*}$ is the distribution function, both functions being estimated at $\varepsilon \lambda / \sigma$.

To obtain a stochastic model of the environmental efficiency measure, the specification form of stochastic production frontier function needs to be specified. In this study, we use a flexible translog functional form to avoid excessive misspecification and ensure an environmental efficiency measure based on random output elasticities and inefficiency effect (Reinhard et al., 1999; Reinhard et al., 2000). Equation (1) is written in translog form as follows:

$$
\begin{aligned}
\ln Y_{i}=\alpha_{0} & +\sum_{n} \alpha_{n} \ln X_{n}+\sum_{l} \beta_{l} \ln Z_{l} \\
& +\frac{1}{2} \sum_{n} \sum_{k} \alpha_{n k} \ln X_{n} \ln X_{k} \\
& +\frac{1}{2} \sum_{l} \sum_{h} \beta_{l h} \ln Z_{l} \ln Z_{h} \\
& +\sum_{n} \sum_{l} \delta_{n l} \ln X_{n} \ln Z_{l} \\
& +v_{i}-u_{i}
\end{aligned}
$$

Where: $\ln Y_{i}$ represents for the natural logarithm of tea yield of the i-th tea farm, $\alpha_{n k}=\alpha_{k n}, \beta_{l j}=\beta_{j l}$.

The logarithm of the tea yield of a technically efficient farmer apart from the statistical noise captured by the error term $v_{i}$ is obtained by setting $u_{i}=0$ in (4). The logarithm of the tea yield of an environmentally efficient farmer apart from the statistical noise is obtained by replacing $Z_{i}$ with $E E_{i} Z_{i}$ and setting $u_{i}=0$ in (4) to obtain:

$$
\begin{aligned}
\ln Y_{i}=\alpha_{0} & +\sum_{n} \alpha_{n} \ln X_{n}+\sum_{l} \beta_{l} \ln \left(E E_{i} Z_{l}\right) \\
& +\frac{1}{2} \sum_{n} \sum_{k} \alpha_{n k} \ln X_{n} \ln X_{k} \\
& +\frac{1}{2} \sum_{l} \sum_{h} \beta_{l h} \ln \left(E E_{i} Z_{l}\right) \ln \left(E E_{i} Z_{h}\right) \\
& +\sum_{n} \sum_{l} \delta_{n l} \ln X_{n} \ln \left(E E_{i} Z_{l}\right) \\
& +v_{i}
\end{aligned}
$$

The output of the farm under consideration is defined in (4) to be equal to the output of the environmentally efficient farm defined in (5). Setting (4) and (5) equal permits the isolation of the logarithm of the stochastic environmental efficiency measure:

$$
\begin{aligned}
\sum_{l} \beta_{l} \ln E E_{i} & +\sum_{n} \sum_{l} \delta_{n l} \ln X_{n} \ln E E_{i} \\
& +\frac{1}{2} \sum_{l} \sum_{h} \beta_{l h}\left[\left(\ln E E_{i}\right)^{2}\right. \\
+ & \left.\ln E E_{i}\left(\ln Z_{l}+\ln Z_{h}\right)\right]+u_{i}=0
\end{aligned}
$$

resulting in

$$
\frac{1}{2} \sum_{l} \sum_{h} \beta_{l h}\left(\ln E E_{i}\right)^{2}+\phi_{i}\left(\ln E E_{i}\right)+u_{i}=0
$$

Where: $\phi_{i}=\sum_{l} \beta_{l}+\sum_{n} \sum_{l} \delta_{n l} \ln X_{n}+\frac{1}{2} \sum_{l} \sum_{h} \beta_{l h}\left(\ln Z_{l}+\right.$ $\left.\ln Z_{h}\right)$. The $\phi_{i}$ term is equal to $\sum_{l}\left(\partial \ln Y / \partial Z_{l}\right)$, the sum of output elasticities with respect to the environmentally detrimental inputs (Reinhard and Thijssen, 2000).

Application for the quaratic equation formula (7) gives the solution for the variable $\ln E E_{i}$ :

$$
\ln E E_{i}=\frac{-\phi_{i} \pm \sqrt{\phi_{i}^{2}-2 u_{i} \sum_{l} \sum_{h} \beta_{l h}}}{\sum_{l} \Sigma_{h} \beta_{l h}}
$$

According to Reinhard et al. (1999), Reinhard and Thijssen (2000), environmental efficiency is caculated using the positive sign of the quadratic equation (8) because the technically efficient farm is essentially environmentally efficient. Finally, the environmental efficiency is estimated as follows:

$$
E E_{i}=\exp \left(\frac{-\phi_{i}+\sqrt{\phi_{i}^{2}-2 u_{i} \sum_{l} \sum_{h} \beta_{l h}}}{\sum_{l} \sum_{h} \beta_{l h}}\right)
$$

To get insights, it is essential to consider economic loss for each tea farm due to environmentally inefficiency. Total economic loss of the $i$-th tea farm is calculated in a manner similar to Tu (2015):

$$
E L_{i}=\left(1-E E_{i}\right) T C_{i}
$$

Where: $E L_{i}$ is economic loss, $E E_{i}$ is the environmental efficiency, and $T C_{i}$ is total cost of bad inputs such as fertilizer and pesticide.

\section{Study Area and Data}

The survey was carried out in Thai Nguyen, which is the largest tea-planting and producing province in the mountainous northern region of Vietnam with 17,300 ha of tea trees yielding about 184,400 tons per year (GSO 2013). In two famous tea-producing districts (Dong Hy district and Thai Nguyen city) in Thai Nguyen province, four representative communes (Tan Cuong, Phuc Xuan, 
Minh Lap and Song Cau) were chosen for data collection. The selected tea farms are representative of topographical conditions in tea production areas of Thai Nguyen province. Tan Cuong and Phuc Xuan commune are administratively in Thai Nguyen city. Tan Cuong is well known for having the highest quality tea in Vietnam. Most of the tea farms are situated along the Cong River where fields are flatter (with $20 \%$ slope), whereas the farms in Phuc Xuan commune are grown on hillsides and uplands. Two communes, Minh Lap and Song Cau, are in Dong Hy district. Minh Lap commune is located about $24 \mathrm{~km}$ east of Thai Nguyen town (the center of Thai Nguyen city) and borders the sides of the Cau River. Most of the tea farms in the Minh Lap commune are on uplands and hillsides with slopes ranging from 15\% to 30\%. Song Cau commune, in contrast, is located in the northeast and about $20 \mathrm{~km}$ from Thai Nguyen town. Tea farms in the Song Cau commune are similar to those in the Minh Lap.

Data on output, conventional and environmentally detrimental inputs of tea production were collected via face-to-face interviews with 243 randomly selected tea farmers from April to December 2014. A pilot survey was held to revise the structure and clarity of the questionnaire.

In the analysis, the output variable is the total fresh tea yield measured in kilograms. The environmentally detrimental inputs considered are fertilizers including nitrogenous, phosphate, potash, complex and others (measured in kilograms), and pesticides (measured in liters), while conventional inputs are labor (measured in man-days), irrigation water (measured in m3), capital consisting of machine expenses (measured in thousand VND), and other costs in tea production (measured in thousand VND). As these inputs are dependent on land, the foundation of agricultural production, land is considered as the fixed factor in agricultural production and other inputs as variable factors. Therefore, the input and output variables are identified in per hectare terms, with the purpose of separating land and variable inputs in this study. Table 1 presents summary statistics of the output and input variables used in the environmental efficiency measurement.

Descriptive statistics show that the variation in inputs used and output produced is considerably large, especially environmentally detrimental inputs. The average tea yield is 14,319.76 kilograms and ranges from 10,028.64 kilograms to $17,740.02$ kilograms. The mean fertilizer level applied was 1,069.74 kilograms per hectare. There was a high variation in the application of this input in tea farms with the range from 506.17 kilograms to $1,768.52$ kilograms. The average use of pesticide is approximately 120.82 liters per hectare, varying between 62.95 liter and 200 liters.

STATA software version 11 is used to estimate a stochastic production frontier and calculate environmental efficiency in this study.

\section{RESULTS}

Firstly, we use the ordinary least square (OLS) regression to determine the variables that significantly affect output (Table 1). The results from the OLS regression show that five variables, Fertilizer, Pesticide, Labor, Irrigation water, and Capital, were significant at the $5 \%$ level, while the last variable Other cost was not significant. For this reason, the Other cost variable was removed from the estimation of the stochastic production frontier. In order to specify the production function form, we continued testing the Cobb-Douglas (CD) against the translog form using the likelihood ratio (LR) test (Coelli et al., 2005). The null hypothesis is that the CD production function form is used. The test results indicate that $\mathrm{LR}=50.07>\chi_{(15,1 \%)}^{2}=48.27$, which means that we reject the Cobb-Douglas form. We therefore decided to use the translog stochastic frontier production function for this study. To test for multicollinearity and heteroskedasticity, which can cause bias in estimation of production model, we apply the Variance Inflation Factor (VIF) and Breusch-Pagan/Cook-Weisberg tests (Wooldridge 2012). The results indicate that there is no multicollinearity (mean value of VIF $=1.270$ ) or heteroskedasticity (probability of chi-square $=0.808$, accepting the null hypothesis

Table 1. Description of variables in frontier model

\begin{tabular}{|c|c|c|c|c|}
\hline Variables & Mean & Std. Dev. & Min & Max \\
\hline \multicolumn{5}{|l|}{ Tea production characteristics } \\
\hline Fresh tea yield (kg/ha) (Y) & $14,319.76$ & $1,340.90$ & $10,028.64$ & $17,740.02$ \\
\hline \multicolumn{5}{|l|}{ Environmentally detrimental inputs } \\
\hline Fertilizer $(k g / h a)\left(X_{1}\right)$ & $1,069.74$ & 226.21 & 506.17 & $1,768.52$ \\
\hline Pesticide (liter/ha) $\left(X_{2}\right)$ & 120.82 & 23.30 & 62.95 & 200.00 \\
\hline \multicolumn{5}{|l|}{ Conventional inputs } \\
\hline Labor ( $m a n-d a y / h a)\left(X_{3}\right)$ & 398.05 & 132.11 & 169.75 & 976.86 \\
\hline Irrigation water $\left(\mathrm{m}_{3} / \mathrm{ha}\right)\left(X_{4}\right)$ & $1,580.46$ & 556.11 & 429.98 & $3,018.21$ \\
\hline Other cost (thousand VND/ha) $\left(X_{5}\right)$ & $5,072.08$ & 708.89 & $3,395.06$ & $6,983.02$ \\
\hline Capital (thousand VND/ha) $\left(X_{6}\right)$ & $2,384.98$ & $2,238.39$ & 164.99 & $17,045.00$ \\
\hline
\end{tabular}

Note: 1 man-day unit = 8 working hours of an adult

Source: Author's estimation 
of constant variance) in the model. The estimates of the translog production function are presented in Table 2.

The $\mathrm{R}^{2}$ is equal to 0.427 , showing that around 42.7 percent of the variation of output is explained by inputs in the model. Assuming that the inefficiency term follows half normal distribution, the presence or absence of technical inefficiency was tested in the study using log likelihood ratio test (LR) (Coelli et.al 2005). Since the LR test statistic of 23.73 exceeds the $5 \%$ critical value, the null hypothesis that farmers are technically efficient is rejected at the $5 \%$ level, indicating the presence of technical inefficiency in tea production in the northern mountainous region of Vietnam. With the variance explained by technical inefficiency, gamma $\left(\gamma=\sigma_{u}^{2} / \sigma^{2}\right)$ is equal to 0.901 , indicating that technical inefficiency contributes $90.1 \%$ to the total variability of output produced.

Given the parameters from the maximum likelihood estimation in Table (2), the environmental efficiency of all bad inputs as well as individual inputs can be derived using equation (9). Table 3 gives the frequency distribu- tion and cumulative distribution of the efficiency estimates.

As shown in Table 3, the mean EE of all bad inputs is $76.03 \%$, indicating that, conditional on observed levels of conventional inputs, tea farms could reduce by about $23.97 \%$ their consumption of environmentally detrimental inputs, such as chemical fertilizer or pesticide, without changing the current output level. Environmental efficiency scores range from $46.26 \%$ to $97.09 \%$, suggesting that there is great variation among tea farms. The average environmentally efficient farm in the sample could reduce about $21.69 \%$ (i.e., $1-[76.03 / 97.09]$ ) of the consumption of bad inputs. Similarly, the least environmentally efficient could also restrict use of bad inputs by $52.35 \%$ (i.e., 1-[46.26/97.09]). The average EE scores of Fertilizer and Pesticide are $69.80 \%$ and $55.89 \%$, respectively. These results show that, if the farms focus on individual bad input, they may reduce either $30.20 \%$ of present fertilizer use or $44.11 \%$ of current pesticide use, while conserving observed output.

Table 2. The estimated translog production function

\begin{tabular}{|c|c|c|c|c|}
\hline \multirow{2}{*}{ Variables } & \multicolumn{2}{|c|}{ OLS } & \multicolumn{2}{|c|}{ MLE } \\
\hline & Coefficient & S.E & Coefficient & S.E \\
\hline Fertilizer & 7.354 & 1.975 & 6.640 & 1.685 \\
\hline Pesticide & -0.624 & 1.142 & -0.887 & 0.943 \\
\hline Labor & 1.516 & 1.001 & 1.960 & 0.830 \\
\hline Irrigation water & 0.551 & 0.869 & 0.533 & 0.678 \\
\hline Capital & -0.328 & 0.391 & -0.373 & 0.325 \\
\hline Fertilizer $\times$ Fertilizer & -1.061 & 0.284 & -1.039 & 0.231 \\
\hline Fertilizer $\times$ Pesticide & -0.056 & 0.159 & 0.028 & 0.136 \\
\hline Fertilizer $\times$ Labor & -0.081 & 0.104 & -0.112 & 0.085 \\
\hline Fertilizer $\times$ Irrigation water & 0.012 & 0.091 & 0.035 & 0.079 \\
\hline Fertilizer $\times$ Capital & 0.100 & 0.048 & 0.122 & 0.039 \\
\hline Pesticide $\times$ Pesticide & -0.054 & 0.201 & -0.022 & 0.188 \\
\hline Pesticide $\times$ Labor & 0.010 & 0.085 & 0.058 & 0.083 \\
\hline Pesticide $\times$ Capital & 0.031 & 0.036 & 0.015 & 0.031 \\
\hline Pesticide $\times$ Irrigation water & 0.083 & 0.069 & 0.064 & 0.056 \\
\hline Labor $\times$ Labor & -0.040 & 0.092 & -0.102 & 0.077 \\
\hline Labor $\times$ Capital & -0.013 & 0.027 & 0.002 & 0.022 \\
\hline Labor $\times$ Irrigation water & -0.138 & 0.056 & -0.109 & 0.050 \\
\hline Capital $\times$ Capital & -0.030 & 0.013 & -0.048 & 0.011 \\
\hline Capital $\times$ Irrigation water & -0.028 & 0.023 & -0.026 & 0.019 \\
\hline Irrigation water $\times$ Irrigation water & 0.010 & 0.063 & -0.023 & 0.055 \\
\hline Constant & -20.778 & 9.126 & -18.623 & 7.671 \\
\hline$R^{2}$ & 0.427 & & & \\
\hline$\sigma_{v}$ & & & 0.034 & 0.006 \\
\hline$\sigma_{u}$ & & & 0.104 & 0.009 \\
\hline$\sigma^{2}$ & & & 0.012 & 0.002 \\
\hline$\lambda=\sigma_{u} / \sigma_{v}$ & & & 3.091 & 0.014 \\
\hline$\gamma=\sigma_{u}^{2} / \sigma^{2}$ & & & 0.901 & \\
\hline LR test $\sigma_{u}=0$ & & & 23.73 & \\
\hline
\end{tabular}

Source: Author's estimation 
Table 3. Environmental efficiency distribution

\begin{tabular}{crrr}
\hline Environmental efficiency (\%) & All bad inputs & Fertilizer & Pesticide \\
$\leq 40$ & $0(0.00)$ & $4(1.65)$ & $67(27.57)$ \\
$40-50$ & $5(2.06)$ & $10(4.12)$ & $34(13.99)$ \\
$50-60$ & $25(10.29)$ & $50(20.58)$ & $28(11.52)$ \\
$60-70$ & $46(18.93)$ & $58(23.87)$ & $35(14.40)$ \\
$70-80$ & $66(27.16)$ & $56(23.05)$ & $47(19.34)$ \\
$80-90$ & $69(28.40)$ & $50(20.58)$ & $30(12.35)$ \\
$\geq 90$ & $32(13.17)$ & $15(6.17)$ & $2(0.82)$ \\
Mean & 76.03 & 69.80 & 55.89 \\
Min & 46.26 & 37.17 & 7.07 \\
Max & 97.09 & 96.61 & 90.31 \\
\hline
\end{tabular}

Note. EE indicates Environmental efficiency; the numbers in parentheses indicate percentages Source: Author's estimation

Table 4. Descriptive statistic of economic loss due to environmentally inefficient production

\begin{tabular}{ccccc}
\hline Economic loss & Mean & $75^{\text {th }}$ percentile & Min & Max \\
\cline { 2 - 4 } (Thousand VND) & $10,443.82$ & $14,449.25$ & 968.60 & 34311.52 \\
\hline
\end{tabular}

Source: Author' estimation

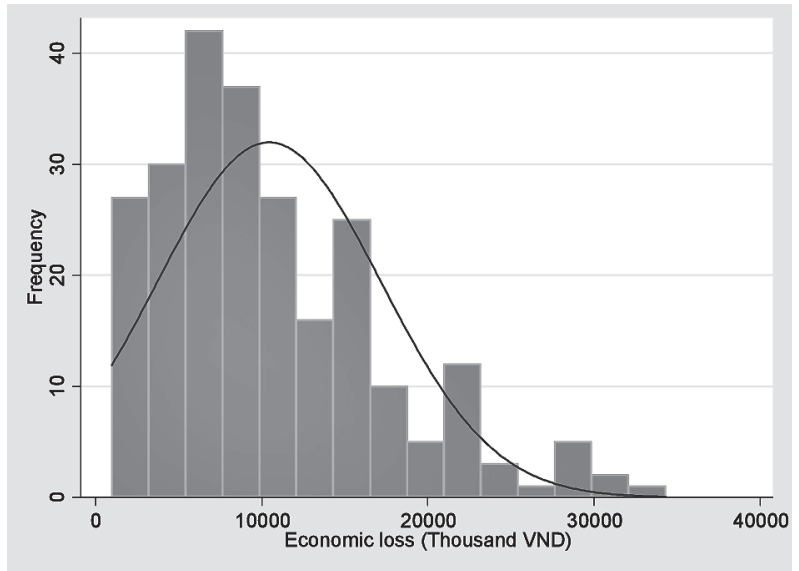

Fig. 1. Distribution of Economic loss.

To get insight into losses that tea farms suffer from environmentally inefficient production, we continue by estimating total economic loss using equation (10). The results are depicted in Table 4 and Figure 1.

The mean economic loss of tea farms was 10,443.82 thousand VND (466 USD ${ }^{1}$ ) per hectare. Furthermore, $75 \%$ of the farms may save $14,449.25$ thousand VND (646 USD) per hectare if environmental inefficiency is removed.

\section{DISCUSSION AND POLICY RECOMMENDATIONS}

In recent years, the tea industry has brought tremendous change to Vietnam. The resulting economic growth has prompted poverty reduction and job creation for millions of poor households, but it has also provoked growing concerns about environmental pollution and ecological deterioration because of environmentally detrimental inputs, which threatens product safety and human health. At present, Vietnamese tea is known in the world market to be of low quality and to have high chemical residue. In this context, the tea sector should be reviewed and adjusted make economically efficient use of environmentally detrimental inputs like chemical fertilizer and pesticide, reduce environmental pollution, ensure food safety and increase its competiveness in international market. By applying stochastic frontier analysis, we obtain tea production's environmental efficiency, based on data collected from 243 Vietnamese tea farmers. The findings in our study may provide policy makers with useful information about the relative performance of chemical fertilizer and pesticide used in tea farming as well as possible ways to improve such performance.

High environmental inefficiency (23.97\%) of both chemical fertilizer and pesticide inputs indicates a potential for substantial reduction of these environmentally detrimental inputs. Through such an adjustment in production operation, on average 10,443.82 thousand VND (466 USD) per hectare could be saved from the cost of inputs. These findings provide empirical evidence for the need to decrease chemical fertilizer and pesticide application in Vietnamese tea production. They contribute to clearing the way for green production in this nationally strategic sector, marked for green growth in the 20112020 period and in the vision for 2050 (Decision 1393/ QD-TTg approved on September 25th 2012 by the Prime

$11 \mathrm{USD}=22,411$ Vietnamese dong (VND) 
Minister). Another implication of environmental efficiency scores is that tea farms within the study area have been intensively using agrochemical inputs. When considering specific input, pesticide is the least environmentally efficient, indicating that it is overused more seriously than chemical fertilizer. This result is consistent with the study of Lamers et al. (2013). It is observed during the field survey that, although farmers recognize the overuse of bad inputs, they feel too vulnerable and insecure to change the current practices. Therefore, they still choose to apply these inputs to avoid crop losses. Focus group discussion and interviews with key informants reveal that the main reasons for this problem are farmers' expectation of high yield from small land holdings and lack of awareness about the risks involved in the overuse of inputs in addition to knowledge about how to use them correctly, which is similar to the findings of Ngo et al. (2001). Other reasons are insufficient guidance and training in inputs use and poor awareness of resource scarcity. Cheap prices, various brands, and easily accessible input markets all encourage farmers to use excessive doses of chemical fertilizer and pesticide.

The conclusions drawn from the analysis suggest that substantial reduction of environmentally detrimental inputs can be attained through raising awareness among farmers about the negative influences of the overuse of agrochemicals and the scarcity of resources. Furthermore, eco-friendly agriculture and integrated pest management practices must be strengthened in the study site. Training programmes and technical activities about the principles and techniques of proper input handling together with demonstration on plots should be better held in the area. It is also essential to promote the use of natural fertilizers such as green compost and manure in tea farming. Finally, increased monitoring of the agrochemical inputs market plays important role in encouraging tea farmers to reduce these inputs.

\section{CONCLUSIONS}

This study shows that Vietnamese tea farms fail to use chemical fertilizer and pesticide inputs efficiently. These environmentally detrimental inputs, particularly pesticide, are overused by the farmers in the research site. The low environmental efficiency estimate (76.03\%) indicates that a $23.97 \%$ reduction in current chemical fertilizer and pesticide application for tea production could be achieved given existing technology without compromising output. Suitable policies that focus on contracting these bad inputs' environmental spillovers may benefit tea farmers by decreasing their production cost $(10,443.82$ thousand VND or 466 USD per hectare) and improving environmental quality.

\section{REFERENCES}

Basnayake, B. and Gunaratne, L. 2000 Estimation of technical efficiency and it's determinants in the tea small holding sector in the Mid Country Wet Zone of Sri Lanka. Economics, 4(Part 1): $137-150$

Baten, A., Kamil, A. A. and Haque, M. A. 2010 Productive effi- ciency of tea industry: A stochastic frontier approach. African journal of Biotechnology, $\mathbf{9}(25)$ : 3808-3816

Battese, G. E. and Corra, G. S. 1977 Estimation of a production frontier model: with application to the pastoral zone of Eastern Australia. Australian journal of agricultural economics, 21(3): 169-179 (doi:http://dx.doi.org/10.1111/j.1467-8489.1977. tb00204.x)

Coelli, T. J., Rao, D. S. P., O'Donnell, C. J. and Battese, G. E. 2005 An introduction to efficiency and productivity analysis. Springer Science \& Business Media, New York, NY 10013, USA

Färe, R., Grosskopf, S., Lovell, C. K. and Pasurka, C. 1989 Multilateral productivity comparisons when some outputs are undesirable: a nonparametric approach. The review of economics and statistics, 71(1): 90-98 (DOI: 10.2307/1928055, stable URL: http://www.jstor.org/stable/1928055)

Farrell, M. J. 1957 The measurement of productive efficiency. Journal of the Royal Statistical Society, Series A (General) 120(3): 253-290 (doi:http://dx.doi.org/10.2307/2343100)

GSO. 2011 Statistical year book. General Statistic Office of Vietnam. Statistical Publishing House, Hanoi, Vietnam

GSO. 2013 Planted tea area by province. General Statistic Office of Vietnam. Online data base http://fsiu.mard.gov.vn/data/trongtrot.htm.

Haridas, N., Kumar, S. A., Nerella, V. K., Deepika, M. G. and Jyotishi, A. 2012 Measuring technical efficiency in tea plantations in India: A panel data analysis. Working Paper No.132/2012, Amrita School of Business, Coimbatore, Tamil Nadu, India

Hong, N. B. and Yabe, M. 2015 Resource Use Efficiency of Tea Production in Vietnam: Using Translog SFA Model. Journal of Agricultural Science, 7(9): 160-172 (URL: http://dx.doi. org/10.5539/jas.v7n9p160)

Jondrow, J., Lovell, C. K., Materov, I. S. and Schmidt, P. 1982 On the estimation of technical inefficiency in the stochastic frontier production function model. Journal of Econometrics, 19(2): 233-238 (doi:http://dx.doi.org/10.1016/0304-4076(82)90004-5)

Lamers, M., Schreinemachers, P., Ingwersen, J., Sangchan, W. Grovermann, C. and Berger, T. 2013 Agricultural Pesticide Use in Mountainous Areas of Thailand and Vietnam: Towards Reducing Exposure and Rationalizing Use. In Sustainable Land Use and Rural Development in Southeast Asia: Innovations and Policies for Mountainous Areas. Springer Science \& Business Media, New York, NY 10013, USA: 149-173

Nghia, T. D. 2008 An analysis of economic and environmental impacts for the transition to organic tea production in the Thai Nguyen province of Vietnam (Doctoral dissertation, University of Hawaii, Manoa, USA). Retrieved from http:// scholarspace.manoa.hawaii.edu/bitstream/handle/10125/ 20757/HAWN_AC1.H3_5132_r.pdf?sequence=1\&origin=public ation_detail

Pittman, R. W. 1983 Multilateral productivity comparisons with undesirable outputs. The Economic Journal, 93: 883-891 (DOI: 10.2307/2232753, Stable URL: http://www.jstor.org/stable/2232753)

Reinhard, S., Lovell, C. K. and Thijssen, G. 1999 Econometric estimation of technical and environmental efficiency: an application to Dutch dairy farms. American Journal of Agricultural Economics, 81(1): 44-60 (doi:http://dx.doi. org/10.2307/1244449)

Reinhard, S. and Thijssen, G. 2000 Nitrogen efficiency of Dutch dairy farms: a shadow cost system approach. European Review of Agricultural Economics, 27(2): 167-186

Saigenji, Y. and Zeller, M. 2009 August Effect of contract farming on productivity and income of small holders: The case of tea production in north-western Vietnam. In Contributed Paper prepared for presentation at the International Association of Agricultural Economists Conference, Beijing, China: $16-22$

Tu, V. H. 2015. Resource use efficiency and economic losses: implications for sustainable rice production in Vietnam. Environment, Development and Sustainability, Springer Netherlands: 1-16 (DOI 10.1007/s10668-015-9724-0) 
Van Der Wal, S. 2008 Sustainability issues in the tea sector: A comparative analysis of six leading producing countries. Stichting Onderzoek Multinationale Ondernemingen, June. Retrieved from http://papers.ssrn.com/sol3/papers.cfm? abstract_id=1660434
Vietnamese Tea Association. 2012 General report in tea sector Wooldridge, J. 2012 Introductory econometrics: A modern approach. South-Western Cengage Learning, 5191 Natorp Boulevard Manson, OH 45040, USA 